\title{
Estimation of flow velocity for a debris flow via the two-phase fluid model
}

\author{
S. Guo ${ }^{1}$, P. Xu' ${ }^{2}$ Z. Zheng ${ }^{2}$, and Y. Gao ${ }^{2}$ \\ ${ }^{1}$ Department of Applied Mathematics, School of Mathematics and Physics, University of Science and Technology Beijing, \\ Beijing, 100083, China \\ ${ }^{2}$ Institute of Applied Mathematics, Academy of Mathematics and Systems Science, Chinese Academy of Sciences, \\ Beijing, 100190, China \\ Correspondence to: P. Xu (xupc@amss.ac.cn)
}

Received: 10 April 2014 - Published in Nonlin. Processes Geophys. Discuss.: 19 June 2014

Revised: 25 December 2014 - Accepted: 7 January 2015 - Published: 3 February 2015

\begin{abstract}
The two-phase fluid model is applied in this study to calculate the steady velocity of a debris flow along a channel bed. By using the momentum equations of the solid and liquid phases in the debris flow together with an empirical formula to describe the interaction between two phases, the steady velocities of the solid and liquid phases are obtained theoretically. The comparison of those velocities obtained by the proposed method with the observed velocities of two realworld debris flows shows that the proposed method can estimate the velocity for a debris flow.
\end{abstract}

\section{Introduction}

A debris flow is the gravity flow of soil, rock and water mixtures, which is frequently initiated by a landslide, and is a common potential hazard throughout the world. For example, the debris flow in Zhouqu (China) on 8 August 2010 killed approximately 1700 people (Wang, 2013), and the debris flow that occurred in Afghanistan on 2 May 2014 killed more than 2000 people (Ahmed and Kakar, 2014). Debris flows can often occur following bush and forest fires. They pose a significant hazard in steep, mountainous areas, and have received particular attention in China, Japan, the USA, Canada, New Zealand, the Philippines, the European Alps, Himalaya-Karakorum, Kazakhstan and Russia.

The typical characteristics of the multi-phase fluid exhibited by a debris flow have been demonstrated by many field observations (O’Brien et al., 1993; Hutter et al., 1996; Hutter and Schneider, 2010a, b). In Takahashi's discussion (Taka- hashi, 2007), it was found that a low-viscous debris flow with a density higher than $1400 \mathrm{~kg} \mathrm{~m}^{-3}$ would contain a nonsediment fluid in which the diameter of granules is smaller than $0.05 \mathrm{~mm}$, whereas a high-viscous debris flow with a density higher than $1900 \mathrm{~kg} \mathrm{~m}^{-3}$ would contain a non-sediment fluid in which the diameter of granules is smaller than $2 \mathrm{~mm}$. We refer to these values as the critical diameters for a debris flow. The non-sediment fluid, composed of water and viscous, fine, non-sediment particles, is in the liquid phase in a debris flow, which behaves as non-Newtonian fluid. The solid phase is composed of particles whose diameter is larger than the critical diameter. This characteristic of a debris flow is aptly described by the two-phase model (Anderson and Jackson, 1967; Iverson, 1997; Iverson and Delinger, 2001; Pitman and Le, 2005; Pudasaini et al., 2005; Pudasaini, 2012). However, the two-phase models describing debris flows are still in the development stages. Although there have recently been substantial advances in simulating real two-phase debris flows (Pudasaini, 2012, 2014), construction of exact solutions is still very challenging (Khattri, 2014).

To understand the dynamics of the debris flow, including its initiation, runout and deposition, and to help analyze these dynamics and the hazard the flow poses, it is important to ascertain the velocity of the debris flow. The reason for this being that soils or rocks, and the fluid involved in a debris flow cause the dynamics of the debris flow to become more complicated, especially the existence of interactions between the solid particles and the liquid (Pudasaini, 2012). As observed in natural debris flow, the velocities of the solid and liquid phases may deviate substantially from each other, es- 
sentially affecting flow mechanics (Prochaska et al., 2008; Pudasaini and Domnik, 2009; Pudasaini, 2011, 2012; Revellino et al., 2004; Rickenmann et al., 2006; Teufelsbauer et al., 2009; Uddin et al., 2001; Yang et al., 2011; Zhu, 1992). Pudasaini (2011) presented exact solutions for debris flow velocity for a fully two-dimensional channel flow in which the velocity field through the flow depth and also along the channel were derived analytically. Several other models have been introduced to estimate the velocity of the debris flow, such as the Fleishman formula (Fleishman, 1970) and the mean velocity formula (Takahashi, 1991; Hashimoto and Hirano, 1997; Julien and Paris, 2010; Hu et al., 2013). These models provide some rough estimations of the flow velocity and are applied to predict the risk of the debris flow. However, the assumption of one-phase flow for these models leads to large modeling errors. Few theoretical results have been obtained to estimate the solid- and liquid-phase velocities for a two-phase debris flow (Chen et al., 2004, 2006). Although some empirical formulae have been introduced to calculate the velocity of a debris flow at special locations, such as the K631 debris flow located on the Tianshan highway in Xinjiang Province of China and the Pingchuan debris flow located on the trunk highway from Xichang City to Muli County in Liangshan Yi Autonomous Prefecture, Sichuan Province, China (Chen et al., 2006). Nevertheless, there is no general formula for calculating the velocity of a debris flow.

In this study, the two-phase flow model is applied to analyze the velocity of a debris flow. To focus on the velocity of the debris flow along the channel, a simplified, onedimensional, two-phase model is considered here, and the motion equations governing the solid and liquid phases are deduced. Following Bagnold (1954), the interaction between the solid and liquid phases is obtained and the velocities of the solid and liquid phases in a debris flow are derived theoretically. This result provides a new theoretical method for estimating the velocities of the solid and liquid phases, which would be useful for evaluating the damage caused by a debris flow, estimating its arrival time, simulating its deposition area, and predicting risk. By comparing the theoretical results for the velocity and the empirical formulae for two natural debris processes, the numerical results show that the proposed method could more accurately provide velocities of solid and liquid phases for a debris flow.

This study is arranged as follows: in Sect. 2, the formulae to calculate the velocities of a debris flow are deduced, and in Sect. 3, the numerical validation of the theoretical results is made by means of two real-world debris flows. The conclusions are presented in Sect. 4.

\section{Velocity estimation of a debris flow}

Two difficulties arise in the calculation of the velocity of a debris flow: firstly, the diameters of the solid phase particles have a wide range, and secondly, the interaction between the solid phase particles and liquid phase slurry is difficult to describe exactly. However, recently, by developing a general two-phase debris flow model, Pudasaini (2012) included several important physical aspects of the real two-phase debris mass flows with strong phase-interactions, including the generalized drag, virtual mass force, Newtonian, and solid particle concentration gradient enhanced non-Newtonian viscous stresses. These model equations have also been put in well structured and conservative form. Numerical simulations and possible applications of these models can be found in Pudasaini (2014), Pudasaini and Miller (2012a, b). In order to deal with solid particles with different diameters, the diameterequivalent method (Brunelli, 1987; Chen et al., 2004), which treats all particles with different diameters as the particles with the same diameter, is applied in this study.

In order to build a simple model for a debris flow to estimate the velocities of its solid and liquid phases, the following assumptions are made:

1. The downstream is set as the $x$ direction, while the vertical direction to the channel bed is the $y$ direction (see Fig. 1) and Fig. 1a see Chen et al. (2006). We assume that the velocity along the $y$ direction is uniform, and thus the one-dimensional model is considered.

2. No mass entrainment is considered, and there is no transformation between the solid phase particles and liquid phase slurry (Chen et al., 2006). Three inner forces are involved in the model: the interactions among the solid phase particles, the interactions in liquid phase slurry and the interactions between the solid phase particles and liquid phase slurry.

3. A debris flow is assumed to be a homogeneous flow (Major and Iverson, 1999; Kaitna et al., 2007).

With these assumptions, and following the two-phase flow theory (see, e.g., Pudasaini, 2012 for more detail), the governing equations for a debris flow are obtained, which are written separately for the solid and liquid phases, denoted by subscripts "s" and "f", respectively. The mass conservation equations for the two phases are written as

$$
\begin{aligned}
& \frac{\partial}{\partial t}\left(\rho_{\mathrm{s}} \varphi_{\mathrm{s}}\right)+\frac{\partial}{\partial x}\left(\rho_{\mathrm{s}} \varphi_{\mathrm{s}} v_{\mathrm{s}}\right)=0, \\
& \frac{\partial}{\partial t}\left(\rho_{\mathrm{f}} \varphi_{\mathrm{f}}\right)+\frac{\partial}{\partial x}\left(\rho_{\mathrm{f}} \varphi_{\mathrm{f}} v_{\mathrm{f}}\right)=0,
\end{aligned}
$$

where $\varphi_{\mathrm{s}}$ is the solid volume fraction and $\varphi_{\mathrm{f}}=1-\varphi_{\mathrm{s}}, \rho_{\mathrm{s}}$ and $\rho_{\mathrm{f}}$ are the densities of solid phase particles and liquid phase slurry, respectively, and $v_{\mathrm{s}}$ and $v_{\mathrm{f}}$ are the velocities of the solid constituent and liquid constituent, respectively. 


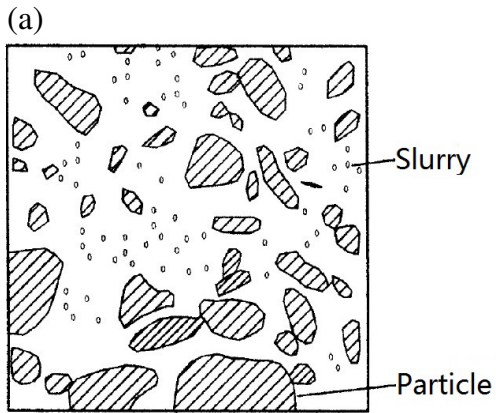

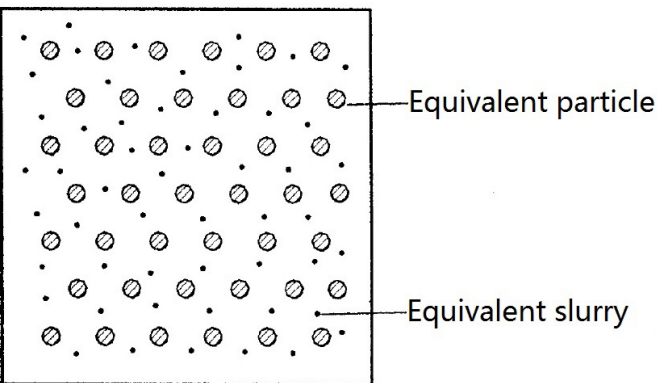

(b)

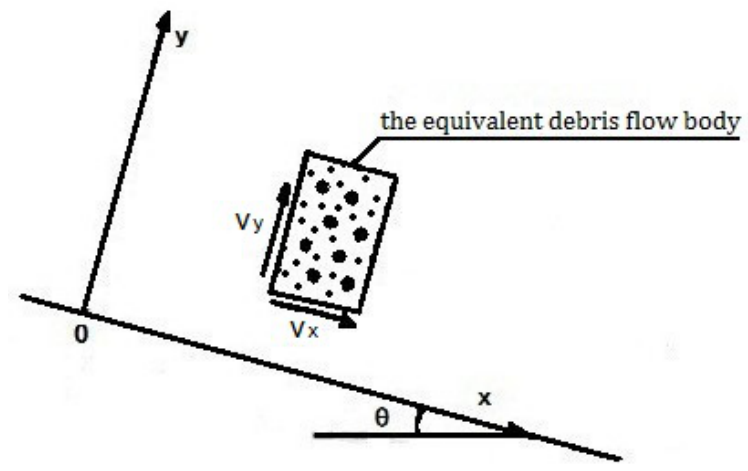

Figure 1. Configuration of the equivalent two-phase debris flow: $x$ indicates downstream direction, $y$ indicates normal to the slope, $\theta$ indicates slope angle, $v_{x}$ and $v_{y}$ indicate the velocity components along the coordinate axes $x$ and $y$, respectively.

The momentum equations for the two phases take the forms (with the buoyancy effect considered)

$$
\begin{aligned}
& \varphi_{\mathrm{s}} \rho_{\mathrm{s}}\left(\frac{\partial v_{\mathrm{s}}}{\partial t}+v_{\mathrm{s}} \frac{\partial v_{\mathrm{s}}}{\partial x}\right)=b_{\mathrm{s}}+f_{\mathrm{s}}-\varphi_{\mathrm{s}} \frac{\partial P_{\mathrm{s}}}{\partial x} \\
& \varphi_{\mathrm{f}} \rho_{\mathrm{f}}\left(\frac{\partial v_{\mathrm{s}}}{\partial t}+v_{\mathrm{f}} \frac{\partial v_{\mathrm{f}}}{\partial x}\right)=b_{\mathrm{f}}+f_{\mathrm{f}}-\varphi_{\mathrm{f}} \frac{\partial P_{\mathrm{f}}}{\partial x} .
\end{aligned}
$$

For detailed model derivation, and how different types of forces and interactions can arise and should be introduced in a real two-phase mass flow model, we refer to Pudasaini (2012).

In order to estimate the velocities of a debris flow using Eqs. (3) and (4), the volume forces $\left(b_{\mathrm{s}}\right.$ and $\left.b_{\mathrm{f}}\right)$, pressures $\left(P_{\mathrm{s}}\right.$ and $\left.P_{\mathrm{f}}\right)$, and surface forces $\left(f_{\mathrm{s}}\right.$ and $\left.f_{\mathrm{f}}\right)$ other than pressure (e.g., liquid resistance, apparent mass force derived from acceleration and difference of velocity, and interaction between particles, see Chen et al., 2006) firstly need to be given. The pressure $P$ for a debris flow can be calculated by

$P=k \rho v^{2}$,

where $k$ is the pressure coefficient of the debris flow body, $v$ is the velocity of the debris flow body, and the density $\rho$ of the debris flow takes the form $\rho=\varphi_{\mathrm{s}} \rho_{\mathrm{s}}+\varphi_{\mathrm{f}} \rho_{\mathrm{f}}$,

and the pressure coefficient $k$ is about 2.4-3.0 for a viscous debris flow; $k$ is about 3.5-4.0 for a thin debris flow (Chen et al., 2011). According to Eq. (5), the pressures of the solid and liquid phases can be rewritten as

$P_{\mathrm{s}}=k \rho_{\mathrm{s}} v_{\mathrm{s}}^{2}$,
$P_{\mathrm{f}}=k \rho_{\mathrm{f}} v_{\mathrm{f}}^{2}$.

The velocity of the debris flow takes the form

$\bar{v}=\frac{\rho_{\mathrm{s}} \varphi_{\mathrm{s}} v_{\mathrm{s}}+\rho_{\mathrm{f}} \varphi_{\mathrm{f}} v_{\mathrm{f}}}{\rho}$.

By considering the gravity and the buoyancy of solid particles, the volume force of the solid phase is written as

$b_{\mathrm{S}}=\varphi_{\mathrm{s}}\left(\rho_{\mathrm{s}}-\rho_{\mathrm{f}}\right) g \sin \theta$,

which is related to the buoyancy reduced normal load (see, e.g., Pitman and Le, 2005; Pudasaini, 2012), where $g$ is the gravity acceleration and $\theta$ is the slope angle of debris flow channel. The volume force of the liquid phase is written as

$b_{\mathrm{f}}=\varphi_{\mathrm{f}} \rho_{\mathrm{f}} g \sin \theta$. 
For two-phase debris flow, the surface forces on a control volume can been divided into four parts (Chen et al., 2006). The surface forces of the solid phase $f_{\mathrm{s}}$ is divided into two parts: the traction of liquid phase slurry outside the control volume, $f_{\mathrm{s} 1}$, and the force from the solid phase particles outside the control volume, $f_{\mathrm{s} 2}$. Similarly, the surface forces for the liquid phase $f_{\mathrm{f}}$ is divided into two parts: the resistance from the solid phase particles outside the control volume, denoted by $f_{\mathrm{f} 1}$, and the resistance from the liquid phase slurry outside the control volume, denoted by $f_{\mathrm{f} 2}$. The particle number $N$ in a unit volume is given by

$N=\frac{6 \varphi_{\mathrm{s}}}{\pi d_{\mathrm{e}}^{3}}$

where $d_{\mathrm{e}}$ is the equivalent diameter of solid phase particles. The cross-section $A_{0}$ of the solid phase taken as

$A_{0}=\frac{\pi d_{\mathrm{e}}^{2}}{4} N=\frac{3 \varphi_{\mathrm{s}}}{2 d_{\mathrm{e}}}$,

on which the pressure difference between the solid and liquid phases is acting, thus using Eqs. (7) and (8), $f_{\mathrm{s} 1}$ is written as

$f_{\mathrm{s} 1}=\left(P_{\mathrm{f}}-P_{\mathrm{s}}\right) A_{0}=\frac{3 k \varphi_{\mathrm{s}}}{2 d_{\mathrm{e}}}\left(\rho_{\mathrm{f}} v_{\mathrm{f}}^{2}-\rho_{\mathrm{s}} v_{\mathrm{s}}^{2}\right)$.

Further, the traction from the liquid phase slurry and the resistance from the solid phase particles outside the control volume are equal and opposite, i.e.,

$f_{\mathrm{s} 1}=-f_{\mathrm{f} 1}$.

The force from the solid particles outside the control volume mainly appears in the form of impact among all the solid particles. The mechanical effects of impact appear as the dispersion stress, $P_{0}$, and the shear stress among the particles, $T_{0}$ (Chien, 1989). Following Bagnold (1954), $P_{0}$ and $T_{0}$ can be written as

$P_{0}=0.040 \rho_{\mathrm{s}}\left(\lambda d_{\mathrm{e}}\right)^{2}\left(\frac{\mathrm{d} v_{\mathrm{s} y}}{\mathrm{~d} y}\right)^{2}$,
$T_{0}=0.013 \rho_{\mathrm{s}}\left(\lambda d_{\mathrm{e}}\right)^{2}\left(\frac{\mathrm{d} v_{\mathrm{s} y}}{\mathrm{~d} y}\right)^{2}$,

where $\lambda=1 /\left[\left(\varphi_{\mathrm{s}}^{0} / \varphi_{\mathrm{s}}\right)^{1 / 3}-1\right]$ is the linear fraction for the solid particles in a debris flow, here $\varphi_{\mathrm{s}}^{0}$ is the maximum possible static volume fraction for the solid particles. Thus $f_{\mathrm{s} 2}$ takes the form

$f_{\mathrm{s} 2}=\int_{0}^{d_{0}}\left(P_{0}+T_{0}\right) \mathrm{d} y=\int_{0}^{d_{0}} 0.053 \rho_{\mathrm{s}}\left(\lambda d_{\mathrm{e}}\right)^{2}\left(\frac{\mathrm{d} v_{\mathrm{s} y}}{\mathrm{~d} y}\right)^{2} \mathrm{~d} y$,

where $d_{0}$ is the equivalent height of the control volume for debris flow.

As the liquid phase slurry in a debris flow can be regarded as a generalized Bingham viscoplastic material (Takahashi,
2007; Chen et al., 2006), the rheological equation of the Bingham material can reflect the internal viscous resistance of liquid phase slurry (Chen et al., 2006), i.e.,

$\tau=\tau_{B}+\mu \frac{\mathrm{d} v_{\mathrm{f} y}}{\mathrm{~d} y}-\rho_{\mathrm{f}} l^{2}\left(\frac{\mathrm{d} v_{\mathrm{f} y}}{\mathrm{~d} y}\right)^{2}$,

where $\tau_{B}$ is the yielding stress of liquid phase slurry, $\mu$ is the viscous coefficient of liquid phase slurry, and $l$ is the moving distance of eddies in the liquid phase slurry under the fluctuation effect, which can be written as $l=\eta y$, where $\eta$ is the turbulence constant obtained by experiment. Then, the resistance of liquid phase slurry $f_{\mathrm{f} 2}$ can be written as (see also Chen et al., 2006)

$f_{\mathrm{f} 2}=\int_{0}^{d_{0}} \tau \mathrm{d} y=\int_{0}^{d_{0}}\left[\tau_{B}+\mu \frac{\mathrm{d} v_{\mathrm{f} y}}{\mathrm{~d} y}-\rho_{\mathrm{f}} l^{2}\left(\frac{\mathrm{d} v_{\mathrm{f} y}}{\mathrm{~d} y}\right)^{2}\right] \mathrm{d} y$.

Now, we assume that the velocity of liquid phase slurry with respect to $y$ satisfies a quadratic function (Chen et al., 2006), i.e.,

$v_{\mathrm{f} y}=a y^{2}+b y+c$,

where the coefficients $a, b$ and $c$ are determined by experiments. Then, using Eqs. (17) and (18), we further obtain

$$
\begin{aligned}
f_{\mathrm{f} 2} & =-\frac{4 \rho_{\mathrm{f}} a^{2} \eta^{2} d_{0}^{5}}{5}-a b \rho_{\mathrm{f}} \eta^{2} d_{0}^{4}-\frac{\rho_{\mathrm{f}} b^{2} \eta^{2} d_{0}^{3}}{3}+a \mu d_{0}^{2} \\
& +\left(\tau_{B}+\mu b\right) d_{0} .
\end{aligned}
$$

There are several model parameters in the proposed model including $a, b, c, d_{0}, k$, etc. Constraining these parameters could be challenging. Such parameters, which could also be used as fit parameters, however, do not appear in a real twophase debris flow model such as that presented by Pudasaini (2012).

If the effect of turbulence in the liquid slurry is not considered, then Eq. (19) can be simplified as

$$
f_{\mathrm{f} 2}=a \mu d_{0}^{2}+\left(\tau_{B}+\mu b\right) d_{0} \text {. }
$$

Further, if the velocity of liquid phase slurry with respect to $y$ is assumed to be a linear function, i.e., $a=0$, then Eq. (20) can be simplified as

$f_{\mathrm{f} 2}=\left(\tau_{B}+\mu b\right) d_{0}$.

Combining Eqs. (14) and (16) and neglecting the $y$ variation of $v_{\text {sy }}$ yields

$f_{\mathrm{s}}=f_{\mathrm{s} 1}+f_{\mathrm{s} 2}=\frac{3 k \varphi_{\mathrm{s}}}{2 d_{\mathrm{e}}}\left(\rho_{\mathrm{f}} v_{\mathrm{f}}^{2}-\rho_{\mathrm{s}} v_{\mathrm{s}}^{2}\right)$.

Combining Eqs. (15) and (21) yields

$f_{\mathrm{f}}=-\frac{3 k \varphi_{\mathrm{s}}}{2 d_{\mathrm{e}}}\left(\rho_{\mathrm{f}} v_{\mathrm{f}}^{2}-\rho_{\mathrm{s}} v_{\mathrm{s}}^{2}\right)+\left(\tau_{B}+\mu b\right) d_{0}$.

Substituting Eqs. (7), (10) and (22) into Eq. (3) yields (steady-state flow, see Chen, 1988; Chen et al., 2004; Jan and Shen, 1997) 
$(2 k+1) \frac{1}{2} \rho_{\mathrm{s}} \frac{\mathrm{d} v_{\mathrm{s}}^{2}}{\mathrm{~d} x}=\left(\rho_{\mathrm{s}}-\rho_{\mathrm{f}}\right) g \sin \theta+\frac{3 k}{2 d_{\mathrm{e}}}\left(\rho_{\mathrm{f}} v_{\mathrm{f}}^{2}-\rho_{\mathrm{s}} v_{\mathrm{s}}^{2}\right)$.

Substituting Eqs. (8), (11) and (23) into Eq. (4) yields

$$
\begin{aligned}
(2 k+1) \frac{1}{2} \rho_{\mathrm{f}} \frac{\mathrm{d} v_{\mathrm{f}}^{2}}{\mathrm{~d} x} & =\rho_{\mathrm{f}} g \sin \theta-\frac{3 k \varphi_{\mathrm{s}}}{2 d_{\mathrm{e}} \varphi_{\mathrm{f}}}\left(\rho_{\mathrm{f}} v_{\mathrm{f}}^{2}-\rho_{\mathrm{s}} v_{\mathrm{s}}^{2}\right) \\
& +\frac{\left(\tau_{B}+\mu b\right) d_{0}}{\varphi_{\mathrm{f}}} .
\end{aligned}
$$

Adding Eqs. (24) and (25) together, we obtain

$$
\begin{aligned}
& \frac{2 k+1}{2}\left(\varphi_{\mathrm{s}} \rho_{\mathrm{s}} \frac{\mathrm{d} v_{\mathrm{s}}^{2}}{\mathrm{~d} x}+\varphi_{\mathrm{f}} \rho_{\mathrm{f}} \frac{\mathrm{d} v_{\mathrm{f}}^{2}}{\mathrm{~d} x}\right)=\varphi_{\mathrm{s}}\left(\rho_{\mathrm{s}}-\rho_{\mathrm{f}}\right) g \sin \theta \\
& +\varphi_{\mathrm{f}} \rho_{\mathrm{f}} g \sin \theta+\left(\tau_{B}+\mu b\right) d_{0} .
\end{aligned}
$$

Integrating from 0 to $x$ for Eq. (26) leads to

$$
\begin{aligned}
\frac{1}{2}\left(\varphi_{\mathrm{s}} \rho_{\mathrm{s}} v_{\mathrm{s}}^{2}\right. & \left.+\varphi_{\mathrm{f}} \rho_{\mathrm{f}} v_{\mathrm{f}}^{2}\right)=\frac{x}{2 k+1}\left\{\left[\varphi_{\mathrm{s}} \rho_{\mathrm{s}}+\left(\varphi_{\mathrm{f}}-\varphi_{\mathrm{s}}\right) \rho_{\mathrm{f}}\right]\right. \\
& \left.\times g \sin \theta+\left(\tau_{B}+\mu b\right) d_{0}\right\} .
\end{aligned}
$$

Subtracting Eq. (25) from Eq. (24) leads to

$$
\begin{gathered}
\frac{1}{2}\left(\rho_{\mathrm{s}} \frac{\mathrm{d} v_{\mathrm{s}}^{2}}{\mathrm{~d} x}-\rho_{\mathrm{f}} \frac{\mathrm{d} v_{\mathrm{f}}^{2}}{\mathrm{~d} x}\right)=-\frac{3 k}{(2 k+1) d_{\mathrm{e}} \varphi_{\mathrm{f}}} \frac{1}{2}\left(\rho_{\mathrm{s}} v_{\mathrm{s}}^{2}-\rho_{\mathrm{f}} v_{\mathrm{f}}^{2}\right) \\
-\frac{1}{2 k+1}\left[\left(2 \rho_{\mathrm{f}}-\rho_{\mathrm{s}}\right) g \sin \theta+\frac{\left(\tau_{B}+\mu b\right) d_{0}}{\varphi_{\mathrm{f}}}\right] .
\end{gathered}
$$

Solving this above equation yields

$$
\begin{aligned}
& \frac{1}{2}\left(\rho_{\mathrm{s}} v_{\mathrm{s}}^{2}-\rho_{\mathrm{f}} v_{\mathrm{f}}^{2}\right)=\frac{d_{\mathrm{e}} \varphi_{\mathrm{f}}}{3 k}\left[\left(2 \rho_{\mathrm{f}}-\rho_{\mathrm{s}}\right) g \sin \theta\right. \\
& \left.\quad+\frac{\left(\tau_{B}+\mu b\right) d_{0}}{\varphi_{\mathrm{f}}}\right]\left[\exp \left(\frac{-3 k}{(2 k+1) d_{\mathrm{e}} \varphi_{\mathrm{f}}} x\right)-1\right] .
\end{aligned}
$$

The velocities of the solid and liquid phases for a debris flow are then obtained via Eqs. (27) and (29).

$$
\begin{aligned}
& \frac{1}{2} \rho_{\mathrm{s}} v_{\mathrm{s}}^{2}=\left\{\left[\varphi_{\mathrm{s}} \rho_{\mathrm{s}}+\left(\varphi_{\mathrm{f}}-\varphi_{\mathrm{s}}\right) \rho_{\mathrm{f}}\right] g \sin \theta+\left(\tau_{B}+\mu b\right) d_{0}\right\} \\
& \quad \times \frac{x}{2 k+1}-\frac{d_{\mathrm{e}} \varphi_{\mathrm{f}}^{2}}{3 k}\left[\left(2 \rho_{\mathrm{f}}-\rho_{\mathrm{s}}\right) g \sin \theta+\frac{\left(\tau_{B}+\mu b\right) d_{0}}{\varphi_{\mathrm{f}}}\right] \\
& \quad \times\left[1-\exp \left(\frac{-3 k}{(2 k+1) d_{\mathrm{e}} \varphi_{\mathrm{f}}} x\right)\right], \\
& \frac{1}{2} \rho_{\mathrm{f}} v_{\mathrm{f}}^{2}=\left\{\left[\varphi_{\mathrm{s}} \rho_{\mathrm{s}}+\left(\varphi_{\mathrm{f}}-\varphi_{\mathrm{s}}\right) \rho_{\mathrm{f}}\right] g \sin \theta+\left(\tau_{B}+\mu b\right) d_{0}\right\} \\
& \quad \times \frac{x}{2 k+1}+\frac{d_{\mathrm{e}} \varphi_{\mathrm{s}} \varphi_{\mathrm{f}}}{3 k}\left[\left(2 \rho_{\mathrm{f}}-\rho_{\mathrm{s}}\right) g \sin \theta+\frac{\left(\tau_{B}+\mu b\right) d_{0}}{\varphi_{\mathrm{f}}}\right] \\
& \quad \times\left[1-\exp \left(\frac{-3 k}{(2 k+1) d_{\mathrm{e}} \varphi_{\mathrm{f}}} x\right)\right],
\end{aligned}
$$

where $x$ denotes the downstream distance.
Although the model solutions (Eqs. 30 and 31) providing the velocity estimates for the solid and liquid phases in a debris flow only utilize and retain the impact pressure difference between the solid and the liquid, and the Bingham viscoplastic parameter, they can provide the basic qualitative analysis of the solid and the liquid velocities. In addition, these solutions do not include any information about the volume of the debris material. Nevertheless, to develop velocity solutions for the solid and the liquid phases in a more consistent and physically more meaningful way, one must use a real and general two-phase debris mass flow model, such as the one developed by Pudasaini (2012), that includes strong phase interactions through the generalized drag, virtual mass force, non-Newtonian enhanced viscous stress, and the evolving volume fraction of the solid-phase.

\section{Results and discussion}

In this study, we developed a new formula to estimate the solid- and liquid-phase velocities in a debris flow, which is useful for understanding the dynamics of the debris flow. Equation (27) provides the total kinetic energy of a debris flow, which is

$\left\{\left[\varphi_{\mathrm{s}} \rho_{\mathrm{s}}+\left(\varphi_{\mathrm{f}}-\varphi_{\mathrm{s}}\right) \rho_{\mathrm{f}}\right] g \sin \theta+\left(\tau_{B}+\mu b\right) d_{0}\right\} \frac{x}{2 k+1}$.

The total kinetic energy is combined from two parts: the kinetic energy derived by gravity $M_{1}$ and the kinetic energy derived by the yielding stress $M_{2}$, which are given by

$$
\begin{aligned}
& M_{1}=\left[\varphi_{\mathrm{s}} \rho_{\mathrm{s}}+\left(\varphi_{\mathrm{f}}-\varphi_{\mathrm{s}}\right) \rho_{\mathrm{f}}\right] g \sin \theta \frac{x}{2 k+1}, \\
& M_{2}=\left(\tau_{B}+\mu b\right) d_{0} \frac{x}{2 k+1} .
\end{aligned}
$$

However, Eq. (29) provides the kinetic energy difference between two phases - the solid and liquid phases - and it describes the interaction between two phases. The parameter $d_{\mathrm{c}}$ is referred to as the characteristic scale of a debris flow, which is defined by

$d_{\mathrm{c}}=\frac{d_{\mathrm{e}} \varphi_{\mathrm{f}}}{3 k}$.

Following this fact, the kinetic energy change due to the interaction between two phases is divided into two parts: the kinetic energy derived by gravity $G_{1}$ and the kinetic energy derived by the yielding stress $G_{2}$, which are given by

$$
\begin{aligned}
& G_{1}=\left(2 \rho_{\mathrm{f}}-\rho_{\mathrm{s}}\right) g \sin \theta d_{\mathrm{c}}\left[1-\exp \left(\frac{-x}{d_{\mathrm{c}}(2 k+1)}\right)\right], \\
& G_{2}=\frac{\left(\tau_{B}+\mu b\right) d_{0}}{\varphi_{\mathrm{f}}} d_{\mathrm{c}}\left[1-\exp \left(\frac{-x}{d_{\mathrm{c}}(2 k+1)}\right)\right] .
\end{aligned}
$$

The velocities of the solid and liquid phases in a debris flow are then given by 


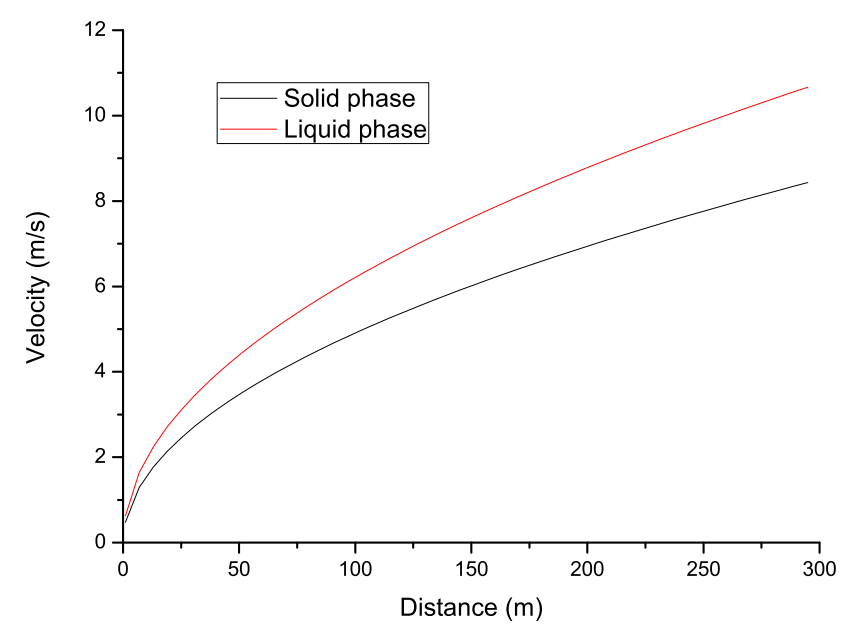

Figure 2. Solid- and liquid-phase velocity variations of a debris flow from the channel position $x=0 \mathrm{~m}$ to the channel position $x=300 \mathrm{~m}: \rho_{\mathrm{s}}=2400 \mathrm{~kg} \mathrm{~m}^{-3}, \rho_{\mathrm{f}}=1500 \mathrm{~kg} \mathrm{~m}^{-3}, d_{\mathrm{e}}=0.10 \mathrm{~m}$, $\varphi_{\mathrm{S}}=0.10, \theta=30^{\circ},\left(\tau_{B}+\mu b\right) d_{0}=100, k=3.72, g=9.8$.

$v_{\mathrm{s}}^{2}=\frac{2}{\rho_{\mathrm{s}}}\left(M_{1}+M_{2}-\varphi_{\mathrm{f}} G_{1}-\varphi_{\mathrm{f}} G_{2}\right)$,

$v_{\mathrm{f}}^{2}=\frac{2}{\rho_{\mathrm{f}}}\left(M_{1}+M_{2}+\varphi_{\mathrm{s}} G_{1}+\varphi_{\mathrm{s}} G_{2}\right)$.

Next, we provide some numerical examples to show the dynamics of a debris flow along the channel. Figure 2 shows some numerical results for the solid- and liquid-phase velocities. The figure indicates that the liquid phase is faster than the solid phase, and the ratio of the velocities for two phases is about 0.790 . Such exact solutions have also been presented previously by Pudasaini (2011) for avalanche and debris flows. We note that, for such a large velocity difference, at least the drag and the virtual mass force must have been included in the model as in Pitman and Le (2005) and Pudasaini (2012). However, the model here does not consider such effects.

The solid- and liquid-phase velocities at a point $300 \mathrm{~m}$ in the channel are shown in Fig. 3 for the different solid volume fractions; it can be seen that the velocity of a debris flow decreases as the solid volume fraction increases. However, $10 \%$ increase in the solid volume fraction resulted only in very slight decrease in the solid and liquid velocities.

The solid- and liquid-phase velocities at $300 \mathrm{~m}$ in the channel are shown in Fig. 4 for the different equivalent diameters of solid particles. Here it can be seen that, as the equivalent diameter of solid particles increases, the solid-phase velocity of a debris flow decreases very slowly whereas the liquidphase velocity increases very slowly. However, a $10 \%$ increase in the equivalent diameters of solid particles resulted in almost no change in the solid and liquid velocities. Such discrepancies may have emerged due to the very simplified model consideration, or some possible inconsistencies in the use of the rheological models considered here. These prob-

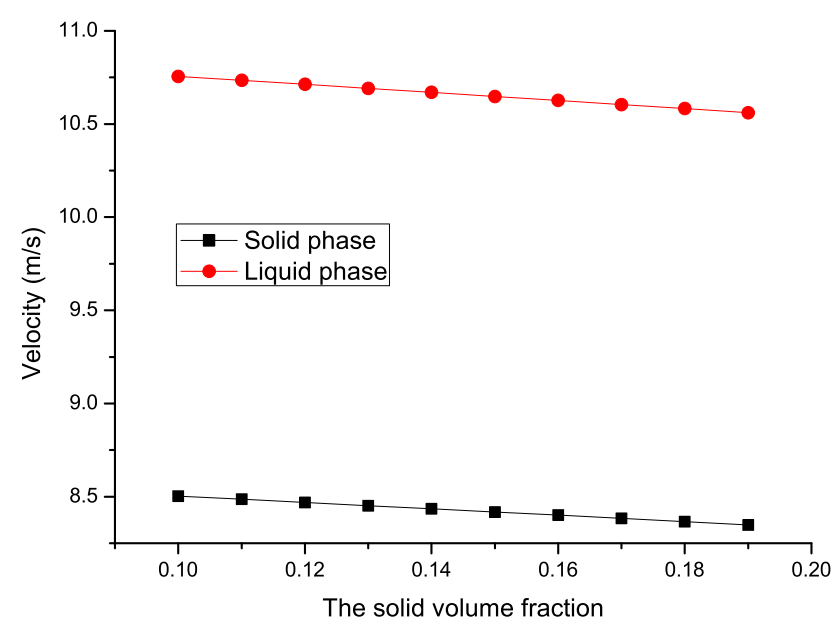

Figure 3. Solid- and liquid-phase velocities of a debris flow at the channel position $x=300 \mathrm{~m}$ for different values of the solid volume fraction parameters: $\rho_{\mathrm{s}}=2400 \mathrm{~kg} \mathrm{~m}^{-3}, \rho_{\mathrm{f}}=1500 \mathrm{~kg} \mathrm{~m}^{-3}$, $d_{\mathrm{e}}=0.10 \mathrm{~m}, \quad \varphi_{\mathrm{s}}=0.10-0.19, \quad \theta=30^{\circ}, \quad\left(\tau_{B}+\mu b\right) d_{0}=100$, $k=3.72, g=9.8$.

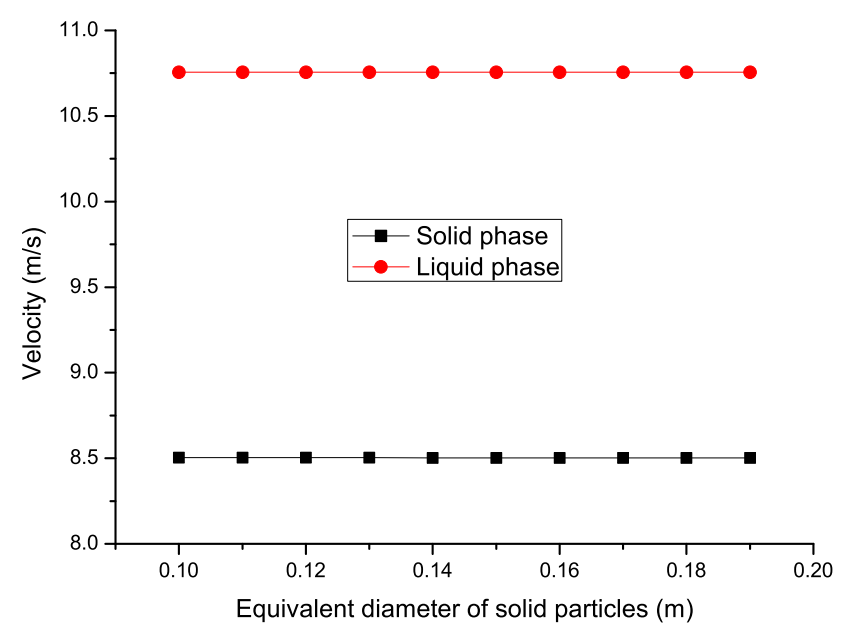

Figure 4. Solid- and liquid-phase velocities of a debris flow at the channel position $x=300 \mathrm{~m}$ for different values of the solid equivalent diameter parameters: $\rho_{\mathrm{s}}=2400 \mathrm{~kg} \mathrm{~m}^{-3}, \rho_{\mathrm{f}}=1500 \mathrm{~kg} \mathrm{~m}^{-3}$, $d_{\mathrm{e}}=0.10-0.19 \mathrm{~m}, \quad \varphi_{\mathrm{s}}=0.10, \quad \theta=30^{\circ}, \quad\left(\tau_{B}+\mu b\right) d_{0}=100$, $k=3.72, g=9.8$.

lems could have been avoided by using a more complete and real two-phase debris flow model (Pudasaini, 2012) which included strong phase interactions.

In order to validate the estimation of velocities presented above, two real-world debris flows - the K631 debris flow located on the Tianshan highway in Xinjiang Province and the Pingchuan debris flow located on the trunk highway from Xichang City to Muli County in Liangshan Yi Autonomous Prefecture, Sichuan Province - are considered. The velocities obtained by observations for the two debris flows, one a viscous debris flow and the other a thin debris flow, are 
Table 1. The results of velocity calculation for the K631 (G217 highway) and Pingchuan debris flows.

\begin{tabular}{lccccccccc}
\hline Name & $\varphi_{\mathrm{S}}$ & $\begin{array}{c}\rho_{\mathrm{s}} \\
\left(\mathrm{kg} \mathrm{m}^{-3}\right)\end{array}$ & $\begin{array}{c}\rho_{\mathrm{f}} \\
\left(\mathrm{kg} \mathrm{m}^{-3}\right)\end{array}$ & $\begin{array}{c}d_{\mathrm{e}} \\
(\mathrm{m})\end{array}$ & $\begin{array}{c}v_{\mathrm{s}} \\
\left(\mathrm{m} \mathrm{s}^{-1}\right)\end{array}$ & $\begin{array}{c}v_{\mathrm{f}} \\
\left(\mathrm{m} \mathrm{s}^{-1}\right)\end{array}$ & $\begin{array}{c}\bar{v}_{1} \\
\left(\mathrm{~m} \mathrm{~s}^{-1}\right)\end{array}$ & $\begin{array}{c}\bar{v}_{2} \\
\left(\mathrm{~m} \mathrm{~s}^{-1}\right)\end{array}$ & $\begin{array}{c}\bar{v}_{3} \\
\left(\mathrm{~m} \mathrm{~s}^{-1}\right)\end{array}$ \\
\hline K631 & 0.0902 & 2500 & 1660 & 0.1033 & 8.43 & 11.97 & 11.59 & 11.72 & 11.51 \\
Pingchuan & 0.0497 & 2400 & 1500 & 0.0816 & 8.97 & 10.41 & 9.70 & 11.14 & 10.30 \\
\hline
\end{tabular}

$\bar{v}_{1}$ is the velocity of debris flow obtained from field observations (Chen et al., 2004), $\bar{v}_{2}$ is the velocity of debris flow calculated by Chen et al. (2006), and $\bar{v}_{3}$ is the velocity of debris flow calculated from Eq. (11).

$11.59 \mathrm{~m} \mathrm{~s}^{-1}$ and $9.70 \mathrm{~m} \mathrm{~s}^{-1}$, respectively (see Table 1). Following Chien (1989), particles of diameter less than $0.1 \mathrm{~m}$ in a viscous debris flow often move in a certain direction with the same velocity, while particles of diameter over $0.1 \mathrm{~m}$ are close to jumping or rolling in a debris flow channel. However, the diameter of a particle in suspension in a thin debris flow is less than $0.02 \mathrm{~m}$. Thus, particles greater than $0.02 \mathrm{~m}$ in diameter are regarded as the equivalent liquid phase slurry, and the others are classified as solid phase particles (Chen et al., 2006). The related parameters (see also Chen et al., 2006) were obtained through analyzing samples at the location. Comparison of the theoretical results and the experiential results shows that the estimation method for the velocities of a debris flow can be effectively used for a real-world debris flow (see Table 1).

\section{Conclusions}

A one-dimensional model for a debris flow has been introduced to estimate the velocities of the solid and liquid phases. By applying the specific form of the volume force and the surface forces for the solid and liquid phases, theoretical results are used to estimate the velocities of the solid and liquid phases. These results are found to be valid by comparing the theoretical results with the experiential data for two real-world debris flows. Furthermore, the theoretical methods can estimate the velocities of a debris flow with different solid volume fraction parameters and different equivalent diameter parameters, which makes the theoretical results more useful for analyzing the debris flow dynamics, including the associated kinetic energy and impact forces.

Acknowledgements. The authors wish to thank the editor and anonymous reviewers for their helpful and valuable comments, which greatly improved this paper. This work was supported by the Fundamental Research Funds for the Central Universities (grant no. FRF-BY-14-036) and National Natural Science Foundation of China (grant nos. 11071238 and 11471034) and the National Center for Mathematics and Interdisciplinary Sciences, CAS and the Key Lab of Random Complex Structures and Data Science, CAS.

Edited by: A. Baas

Reviewed by: two anonymous referees

\section{References}

Ahmed, A. and Kakar, H.: Aid effort begins at scene of Afghan landslides, New York Times, 3 May 2014.

Anderson, T. B. and Jackson, R.: Fluid mechanical description of fluidized beds: equations of motion, Ind. Eng. Chem. Fundam., 6, 527-539, 1967.

Bagnold, R. A.: Experiments on a gravity-free dispersion of large solid spheres in a Newtonian fluid under shear, P. Roy. Soc. Lond. A, 225, 49-63, 1954.

Brunelli, S.: Trasporto solido annuo dei corsi d'acqua in funzione delle loro caratteristiche idrologiche e morfologiche, Tesi di Laurea, Università degli Studi di Padova, Padova, 1987.

Chen, C.: Generalized viscoplastic modeling of debris flow, J. Hydraul. Eng., 114, 237-258, 1988.

Chen, H., Tang, H., Ma, Y., and Wu, S.: Research and Control of Debris Flow Along Highway, China Communications Press, Beijing, 86-116, 2004.

Chen, H., Tang, H., and Chen, Y.: Research on method to calculate velocities of solid phase and liquid phase in debris flow, Appl. Math. Mech.-Engl., 27, 399-408, 2006.

Chen, N., Yang, C., Zhou, W., Hu, G., Deng, M., and Yang, K.: Investigation Technology For Debris Flows, Science Press, Beijing, 177-178, 2011.

Chien, N.: Movement of Water with High Sediment, Press of Tsinghua University, Beijing, 151-162, 1989.

Fleishman, S. M.: Seli, Gidrometeoizdat, Leningrad, 1970.

Hashimoto, H. and Hirano, M.: A flow model of hyperconcentrated sand-water mixtures, in: Proc. 1st Int. Conf. on Debris-Flow Hazards Mitigation: Mechanics, Prediction, and Assessment, San Francisco, California, 7-9 August, ASCE, New York, 464-473, 1997.

$\mathrm{Hu}, \mathrm{K}$., Tian, M., and Li, Y.: Influence of flow width on mean velocity of debris flows in wide open channel, J. Hydraul. Eng., 139, 65-69, 2013.

Hutter, K. and Schneider, L.: Important aspects in the formulation of solid-fluid debris-flow models, Part I. Thermodynamic implications, Continuum Mech. Therm., 22, 363-390, 2010a.

Hutter, K. and Schneider, L.: Important aspects in the formulation of solid-fluid debris-flow models, Part II. Constitutive modelling, Continuum Mech. Therm., 22, 391-411, 2010b.

Hutter, K., Svendsen, B., and Rickenmann, D.: Debris flow modelling: a review, Continuum Mech. Therm., 8, 1-35, 1996.

Iverson, R. M.: The physics of debris flows, Rev. Geophys., 35, 245-296, 1997.

Iverson, R. M. and Denlinger, R. P.: Flow of variably fluidized granular masses across three-dimensional terrain, 1. Coulomb mixture theory, J. Geophys. Res., 106, 537-552, 2001. 
Jan, C.-D. and Shen, H. W.: Review dynamic modeling of debris flows, Lect. Notes Earth Sci., 64, 93-116, 1997.

Julien, P. Y. and Paris, M. A.: Mean velocity of mudflows and debris flows, J. Hydraul. Eng., 136, 676-679, 2010.

Kaitna, R., Rickenmann, D., and Schatzmann, M.: Experimental study on rheologic behaviour of debris flow material, Acta Geotech., 2, 71-85, 2007.

Khattri, K. B.: Sub-diffusive and Sub-advective Viscous Fluid Flows in Debris and Porous Media, M. Phil. Dissertation, Kathmandu University, School of Science, Kavre, Dhulikhel, Nepal, 2014.

Major, J. J. and Iverson, R. M.: Debris-flow deposition: effects of pore-fluid pressure and friction concentrated at flow margins, Geol. Soc. Am. Bull., 111, 1424-1434, 1999.

O'Brien, J. S., Julien, P. J., and Fullerton, W. T.: Two-dimensional water flood and mudflow simulation, J. Hydraul. Eng., 119, 244 261, 1993.

Pitman, E. B. and Le, L.: A two-fluid model for avalanche and debris flows, Philos. T. Roy. Soc. A, 363, 1573-1601, 2005.

Prochaska, A. B., Santi, P. M., Higgins, J. D., and Cannon, S. H.: A study of methods to estimate debris flow velocity, Landslides, 5, 431-444, 2008.

Pudasaini, S. P.: Some exact solutions for debris and avalanche flows, Phys. Fluids, 23, 043301, doi:10.1063/1.3570532, 2011.

Pudasaini, S. P.: A general two-phase debris flow model, J. Geophys. Res., 117, F03010, doi:10.1029/2011JF002186, 2012.

Pudasaini, S. P.: Dynamics of submarine debris flow and tsunami, Acta Mech., 225, 2423-2434, doi:10.1007/s00707-014-1126-0, 2014.

Pudasaini, S. P. and Domnik, B.: Energy considerations in accelerating rapid shear granular flows, Nonlin. Processes Geophys., 16, 399-407, doi:10.5194/npg-16-399-2009, 2009.

Pudasaini, S. P. and Miller, S. A.: Buoyancy induced mobility in two-phase debris flow, AIP Conf. Proc., 1479, 149-152, doi:10.1063/1.4756084, 2012a.
Pudasaini, S. P. and Miller, S. A.: A real two-phase submarine debris flow and tsunami, AIP Conf. Proc., 1479, 197-200, doi:10.1063/1.4756096, 2012b.

Pudasaini, S. P., Wang, Y., and Hutter, K.: Modelling debris flows down general channels, Nat. Hazards Earth Syst. Sci., 5, 799819, doi:10.5194/nhess-5-799-2005, 2005.

Revellino, P., Hungr, O., Guadagno, F. M., and Evans, S. G.: Velocity and runout simulation of destructive debris flows and debris avalanches in pyroclastic deposits, Campania region, Italy, Environ. Geol., 45, 295-311, 2004.

Rickenmann, D., Laigle, D., McArdell, B., and Hübl, J.: Comparison of 2D debris-flow simulation models with field events, Comput. Geosci., 10, 241-264, 2006.

Takahashi, T.: Debris Flow, IAHR Monograph Series, A. A. Balkema, Rotterdam, 1991.

Takahashi, T.: Debris Flow: Mechanics, Prediction and Countermeasures, Taylor \& Francis, London, 2007.

Teufelsbauer, H., Wang, Y., Chiou, M. C., and Wu, W.: Flowobstacle interaction in rapid granular avalanches: DEM simulation and comparison with experiment, Granul. Matter, 11, 209220, 2009.

Uddin, M. S., Inaba, H., Yoshida, Y., Itakura, Y., and Kasahara, M.: Large motion estimation by gradient technique-application to debris flow velocity field, Phys. Chem. Earth C, 26, 633-638, 2001.

Wang, G. L.: Lessons learned from protective measures associated with the 2010 Zhouqu debris flow disaster in China, Nat. Hazards, 69, 1835-1847, doi:10.1007/s11069-013-0772-1, 2013.

Yang, H., Wei, F., Hu, K., Chernomorets, S., Hong, Y., Li, X., and Xie, T.: Measuring the internal velocity of debris flows using impact pressure detecting in the flume experiment, J. Mt. Sci., 8, 109-116, 2011.

Zhu, P.: A discussion on the velocity of debris flow, Erosion, Debris Flows and Environment in Mountain Regions (Proceedings of the Chengdu Symposium, July 1992), IAHS Publ., 209, 369374, 1992. 